\title{
Assessment of proton beam ablation in myocardial infarct tissue using delayed contrast-enhanced magnetic resonance imaging (Erratum)
}

M. Rettmann, S. Hohmann, A. Deisher, H. Konishi, J. Kruse, et al.

M. E. Rettmann, S. Hohmann, A. J. Deisher, H. Konishi, J. J. Kruse, L. K. Newman, K. D. Parker, M. G. Herman M.D., D. L. Packer, "Assessment of proton beam ablation in myocardial infarct tissue using delayed contrastenhanced magnetic resonance imaging (Erratum)," Proc. SPIE 11315, Medical Imaging 2020: Image-Guided Procedures, Robotic Interventions, and Modeling, 1131534 (28 April 2020); doi: 10.1117/12.2572836

SPIE. Event: SPIE Medical Imaging, 2020, Houston, Texas, United States 


\section{Assessment of proton beam ablation in myocardial infarct tissue using delayed contrastenhanced magnetic resonance imaging (Eratum)}

M. E. Rettmann, ${ }^{1}$ S. Hohmann, ${ }^{1}$ A. J. Deisher, ${ }^{1}$ H. Konishi, ${ }^{1}$ J. J. Kruse,${ }^{1}$ L. K. Newman, ${ }^{1}$ K. D. Parker, ${ }^{1}$ M. G. Herman, ${ }^{1}$ D. L. Packer ${ }^{1}$

${ }^{1}$ Mayo Clinic (United States))

Proceedings Volume 11315, Medical Imaging 2020: Image-Guided Procedures, Robotic Interventions, and Modeling; 1131511 (2020) https://doi.org/10.1117/12.2550659

Event: SPIE Medical Imaging, 2020, Houston, Texas, United States

Online Publication Date: 16 Ma rch 2020

Enatum Published: 28 A pril 2020

A revised version of this manuscript was published on 28 April 2020. Details of the revision are provided in the text that accompanies this Erratum. The original paper has been updated.

Figure 1 has been updated with figures that more clearly illustrate the workflow of registering the images and transferring the contour.

Original version:
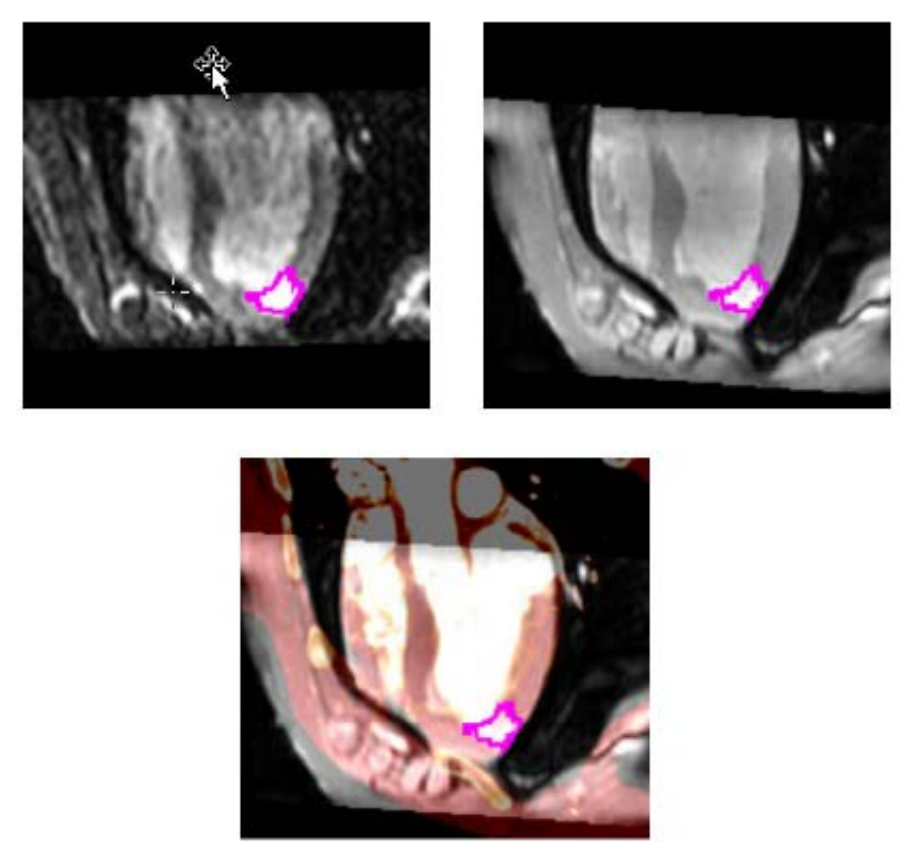

Figure 1. Segmented scar (magenta) on DCE-MRI scan (top left), FIESTA scan (top right), and CT scan (bottom). Bottom figure shows CT (hot metal color scale) overlayed on anatomic FIESTA image (grayscale). 


\section{Revised version:}
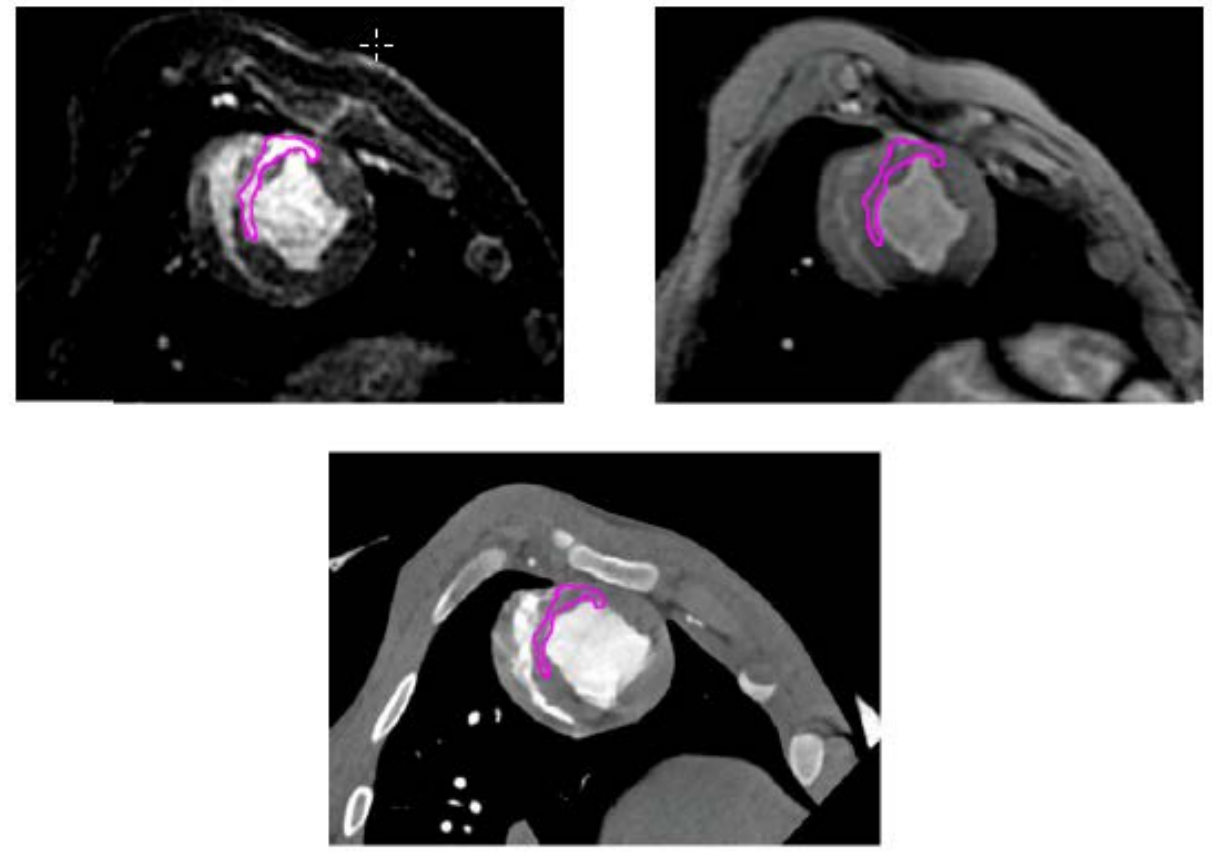

Figure 1. Segmented scar (magenta) on DCE-MRI scan (top left), FIESTA scan (top right), and CT scan (bottom). 